\title{
DISTANTES E PRÓXIMOS: UM ESTUDO SOBRE AS METADES EXOGÂMICAS KAGWAHIVA PARINTINTIN
}

ANGELA KUROVSKI ${ }^{1}$

$U F P R$

\begin{abstract}
RESUMO: $O$ presente estudo apresenta uma análise do sistema dualista Kagwahiva Parintintin, retomando principalmente as reflexões de Kracke (1984a;1984b), Menendez (1989) e Peggion (1996). Procuro evidenciar que o sistema de metades patrilineares - Kwandu/ Myty̆ - regula várias instâncias da vida Kagwahiva, mesmo diante da depopulação sofrida ao longo de um contato desastroso com a sociedade não indígena. $O$ casamento ideal é a exogamia de metades, contudo a busca de casamentos inter étnicos, mais do que sugerir o desuso dos princípios estruturais próprios, frisa exatamente o contrário, uma aplicação destes princípios culturais na situação contemporânea.
\end{abstract}

PALAVRAS CHAVE: metades exogâmicas; contato; Tupi-Kagwahiva; casamentos inter étnicos.

ABSTRACT: This study presents an analysis of the system of exogamous moieties Kagwahiva Parintintin, retaking principally the reflections of Kräcke (1984a, 1984b) Menendez (1989) and Peggion (1996). I attempt to evidence that the system of moieties - Kwandu/Myty - regulates many instances of the Kagwahiva life, despite the depopulation suffered along a disastrous contact with the non-indigenous society. The ideal marriage is the exogamy of moieties, but the search of inter - ethnic marriages, more than suggests the disuse of their own structural principles; emphasizes the opposite, an application of these cultural principles in the contemporary situation.

KEYWORDS: exogamous moieties; contat; Tupi-Kagwahiva; inter-ethnic marriages.

\section{Os Kagwahiva Parintintin}

Os Kagwahiva estão localizados na região dos afluentes orientais do médio rio Madeira e Tapajós. Pertencem a um ramo da família lingüística Tupi-Guarani (RODRIGUES, 1986, P. 39), da qual também

\footnotetext{
${ }^{1}$ Angela Kurovski é Mestre pelo Programa de Pós-graduação em Antropologia Social - Setor Ciências Humanas, Letras e Artes - Universidade Federal do Paraná - Bolsista pela CAPES - março/2003 a março/2005. Atuou em programas de educação escolar Indígena - 1990 - 2006. Ministrou aulas de Antropologia para cursos de Pedagogia. E-mail: kunhaiak@yahoo.com.br .
}

Espaço Ameríndio, Porto Alegre, v. 3, n. 1, p. 61-83, jan./jun. 2009. 
ANGELA KUROVSKI - Distantes e próximos ...

fazem parte os Parintintin, Tenharin, Tenonde, Juma, Urueu-Wau-Wau, Amondawa e Jahoi. Entre seus vizinhos indígenas estão os Pirahã, Torá e Apurinã e regionais da Transamazônica. Este texto trata de um dos grupos kagwahiva que possuem um intenso contato com a sociedade não indígena. A idéia do texto é compreender como os princípios do sistema de metades se expressam na contemporaneidade.

\section{Sistema de metades Kagwahiva}

Internamente, os Kagwahiva (Parintintin, Tenharin, Jahoi, Tenonde e Urueu-Wau-Wau) dividem-se em duas metades patrilineares, Kwandu (gavião) e Myty̆ Nhãgwera (mutum). Segundo informações de Igwa Parintintin, Nhãgwera - nós antigos - se refere aos primeiros da terra e, portanto a metade Myty̆ estaria relacionada ao herói civilizador Mbahira. Os Kagwahiva Tenharin acrescentam o termo - Tarave (arara maracanã) na metade Kwandu, algumas vezes também utilizado pelos Parintintin e definido por eles como sendo o mesmo que Kwandu.

Os Parintintin mencionam oposições e contrastes nas características físicas e comportamentais entre os integrantes das duas metades. Segundo eles, as crianças Kwandu são mais bravas e as Myty̆ mais calmas. A aparência e textura da pele também são utilizadas como elemento distintivo entre as metades. Ao que tudo indica as diferenças entre as duas aves são estendidas aos seres humanos. Kwandu é caçador e indomável, ao contrário de Myty̆ que é criado com animais domésticos no pátio da aldeia.

Como se observa, as aves epónimas são simetricamente opostas: Kwandu - gavião - de coloração clara, voa alto. Myty̆ - mutum coloração escura, voa baixo, é terrestre (KRACKE, 1984a e 1984b; MENENDEZ, 1989; PEGGION, 1996).

Kracke (1984a, p. 198) identificou entre os Kagwahiva Parintintin uma subdivisão das metades, com o nome Gwyray̆'gwara², a qual o autor chamou de um "terceiro clã clandestino". Conforme Kracke, casamentos em uma mesma metade seria uma exceção permitida. Pelos

\footnotetext{
${ }^{2}$ Segundo Betts (1981), o termo significa "parentes dos Parintintin". Kracke (1984a e 1984b, p. 123) definiu como uma seção da metade Kwandu, e significa comedor de pequenos pássaros. Um dos seus entrevistados também traduziu o termo como gavião-tesouro.
} 
ANGELA KUROVSKI - Distantes e próximos ...

seus dados, os casamentos incestuosos ocorriam freqüentemente entre a metade Kwandu e nenhum caso entre os Myty̆, levando a sugerir que os Gwyray̆gwara são assimilados à metade Kwandu, dando origem a três clãs.

A existência de sistemas de metades em diversos grupos tornouse uma questão intrigante para os antropólogos ao longo dos anos. Na América do Sul, as descobertas de organizações dualistas entre povos do Brasil Central com reduzida significação matrimonial abriram margem para novas interpretações sobre estas formas de organização, que se expressavam de modos diversos em diferentes contextos. LéviStrauss, em Estruturas Elementares do Parentesco, nos alerta que a organização dualista não é primeiramente uma instituição. Afirma o autor que se quiséssemos interpretá-la desta maneira seríamos condenados a procurar sem esperança onde começa e onde acaba, e correríamos o risco de sermos lançados no atomismo e no nominalismo de Lowie. É, antes um princípio de organização, capaz de receber aplicações muito diversas, como: regular casamentos, trocas econômicas e rituais, outras vezes somente uma dessas atividades. 0 caráter funcional da organização dualista nem sempre é manifesto. Este princípio é apenas uma modalidade do princípio de reciprocidade (LÉVISTRAUSS, 1982, p. 113-114 e 122).

Em publicação posterior o mesmo autor argumentará que os estudos das organizações dualistas revelam anomalias e contradições em relação à teoria antropológica. As descrições antropológicas das instituições indígenas coincidem com a imagem que os indígenas possuem de sua própria sociedade. Intrigava ao autor se "as organizações dualistas existiam", e, na tentativa de responder esta questão, sugere dois modelos: estrutura diametral e estrutura concêntrica. Aquele apresentando uma estrutura mais simétrica; e o dualismo concêntrico assumindo dicotomias como centro e periferia, feminino/masculino, revelando uma desigualdade implícita, já que os dois elementos são ordenados em relação ao mesmo termo de referência: o centro. Entre os Bororo, Winebago e diversos grupos da Indonésia, o autor observou que as estruturas concêntricas coexistem com muitas outras do tipo diametral. As manifestações do dualismo dariam lugar a uma tríade (LÉVI-STRAUSS, 1996, p. 158-159). 
Este debate sobre o papel da função das metades exogâmicas em certa medida está presente nos estudos antropológicos sobre os Tupi Kagwahiva. Até bem pouco tempo, os grupos Tupi eram considerados desprovidos de qualquer tipo de divisões morfológicas, prerrogativa apenas dos povos Jê. Locais onde apareciam vestígios desta forma de organização eram atribuídos como empréstimos de outros grupos ${ }^{3}$ (LARAIA, 1986; MENENDEZ, 1989). A análise de Kracke (1984a) parece coincidir com esta tendência. Para este autor a fissão em metades é uma instituição adquirida recentemente pelos Parintintin, sendo que não possuem importância na vida cerimonial, não aparecem de forma explícita na mitologia e, embora possam apresentar uma função nominadora em cada estágio do ciclo da vida, na prática, esta função é bastante frouxa. Conforme o autor o sistema de casamento Kagwahiva revela três sistemas separados, operando em diferentes planos: a organização dualista exogâmica, um sistema triádico de clãs exogâmicos (Myty̆ -Kwandu - Gwyrăy'gwara) e a existência de patrilinhias. Menendez (1989), nos seus estudos sobre os Tenharin, ao contrário, sugere que as metades possuem fundamento mítico, além de operarem na nominação, escolha de cônjuges e no estabelecimento de alianças políticas. Da mesma forma, os estudos de Peggion (1996) sobre os Tenharin se contrapõe à tese de Kracke, apresentando uma análise sobre a forma e a função das metades Kagwahiva.

Assim, pois me debruçarei sobre algumas questões apontadas pelos autores mencionados acima, que tratam da função cerimonial, referência às metades na mitologia, metades como reguladoras de alianças matrimoniais e econômicas e o papel na nominação. Ao tentar recuperar estas análises, não é meu objetivo um estudo aprofundado do sistema de organização dualista Kagwahiva, mas apontar algumas questões que considero relevantes para o entendimento das atuais trocas matrimoniais entre os Parintintin.

Iniciarei pelo papel que as metades ocupam no aspecto cerimonial. Nos rituais Kagwahiva as metades operam como distintivo

\footnotetext{
${ }^{3}$ Várias pesquisas etnológicas comprovaram a existência de metades entre grupos Tupi, como nos Mundurucu, Mawé, Parintintin,. Entre os Suruí foram encontrados clãs que podem apontar a existência de duas seções (LARAIA, 1986). Interessante ressaltar que o caso Mundurucu é bastante semelhante aos Parintintin. Os Mundurucu são patrilineares e estão divididos em duas metades, contendo uma série de grupos ou clãs que se casam entre si, mas a residência é uxorilocal provisória.
} 
ANGELA KUROVSKI - Distantes e próximos ...

de grupos, isto é bastante visível, nos dias de hoje, nas cerimônias Kagwahiva Tenharin. Os homens costumam pintar o corpo com jenipapo ou carvão, sendo que integrantes de uma metade devem pintar os da metade oposta.

$\mathrm{Na}$ atualidade, entre os Parintintin, as pinturas corporais masculinas não apresentam diferenças distintivas entre os dois grupos. Todavia, durante os preparativos de rituais que presenciei, reportavamse freqüentemente sobre as diferenças entre pinturas Kwandu e Myty̆. Segundo informações que obtive e dados de Peggion (1996), no passado, as metades distinguiam-se no uso de diferentes produtos empregados na pintura corporal; o jenipapo era utilizado pela metade Myty̆ e o urucu pela Kwandu. Também diferentes plumagens, de acordo com cada metade, eram empregadas para confecção das akanitara (diademas de penas) e demais instrumentos. Por sua vez, as pinturas corporais femininas consistem em pequenas manchas feitas com a ponta dos dedos em tinta de jenipapo, imitando uma onça pintada e algumas linhas finas horizontais nas pernas. As pinturas das mulheres Kwandu se estendem desde o tronco até os pés, enquanto que a das Myty̆ restringe-se à parte inferior do tronco e pernas.

Por ocasião dos rituais, também, observa-se um cuidado na distribuição dos parceiros dançarinos, homens Kwandu necessariamente devem dançar com mulheres Myty̆ ou vice-versa. Na festa da Mbotava Tenharin, Peggion (2004) identificou uma divisão de tarefas, segundo as metades exogâmicas ${ }^{4}$. Os Myty̆ são responsáveis pelo cuidado do moquém da carne de anta, enquanto os Kwandu pelo carregamento do cesto de farinha.

As metades também exprimem uma classificação bipartida do mundo. Os Kagwahiva nos relataram que todas as coisas e os seres podem ser classificados ou repartidos em duas metades. Menendez (1989) obteve alguns exemplos, como demonstrado na tabela abaixo:

\footnotetext{
${ }^{4}$ Os Parintintin não mais realizam a festa Mbotava, contudo ainda, em algumas ocasiões, dançam o Yrerupukuhu (dança das flautas). Nestes eventos identifiquei diferentes traços entre pinturas femininas de acordo com sua metade.
} 
ANGELA KUROVSKI - Distantes e próximos ...

Tabela 1. Classificação Kagwahiva (MENENDEZ,1989, p. 196).

\begin{tabular}{l|l}
\hline Mytỹ & Kwandu \\
Urumutum & Arara Canindé \\
Uruçu & Japu \\
Premu & Tucano \\
Inhambu Grande & Galinha \\
Jacu & Borrachudo \\
Macaco barrigudo & Jacamim \\
Traira & Macaco Prego \\
Matrixão & Surubin \\
Jatuarana & Tucunaré \\
Acará & \\
Milho & Mandioca \\
Banana & Castanheira \\
Batata doce & Caititu \\
Queixada & Anta \\
& Paca \\
Patauá & Cachorro \\
& Fogo-cinza \\
& Ireru (flauta) \\
\hline
\end{tabular}

Esta tabela pode nos sugerir algumas oposições entre as coisas pertencentes a uma ou outra metade, como cor clara $X$ cor escura, alto $X$ baixo, + agricultura $X$ + caça etc. Por outro lado, imediatamente este quadro nos sugere a pergunta se haveria relação entre proibições alimentares e metades. Os Parintintin mantêm a memória de uma série de regras a serem cumpridas sobre os alimentos e condutas, mas, segundo relatos, estas restrições estariam antes relacionadas às fases da vida de uma pessoa, desde a gravidez, o resguardo masculino e feminino, a puberdade, casamento e morte. Entretanto, nos dias de hoje, os Parintintin nem sempre as cumprem na sua totalidade.

No que se refere às regras de alimentação, a escassez de alimentos em determinadas regiões ou períodos é um facilitador à transgressão, ao lado do seu desuso pós-contato. Eis, um exemplo; em uma aldeia, certa vez, uma onça abatida serviu de alimento para todos os moradores, do mesmo modo que um gato maracajá. Tapi'ira'ğa, o caçador da aldeia, revelou que tem conhecimento sobre as proibições acerca destes animais, mas em tempos de penúria não há escolha. 
ANGELA KUROVSKI - Distantes e próximos ...

Manoelzinho Parintintin acrescentou que os jovens não cumprem suas obrigações alimentares, por isto não possuem a força física dos mais velhos. Alimentar-se da carne do mutum, independente da metade que um indivíduo pertença, segundo ele, acarreta velhice precoce, "o cabelo fica branco e tem preguiça de trabalhar" (entrevista realizada em 1997). Sobre o gavião não tenho informações precisas, mas, ao que tudo indica, os Parintintin não se alimentam desta ave. Sabe-se que a caça do Kwanduhu (gavião real) é extremamente perigosa, portanto o caçador deve tomar alguns cuidados, como dividir as penas do animal entre os demais caçadores da aldeia.

Passarei a tratar sobre a função das metades na nominação. Como já mencionei, Kracke (1984a) em "Marriage Practices in Lowland South America" argumenta que poucos nomes próprios correspondem à lista de coisas classificadas em metades. Em outra publicação, também de 1984, menciona a nominação das crianças pós-nascimento, lembrando que o nome de seres mitológicos, como Mbahira, limitava-se às crianças da metade Myty̆ Nhãgwera e os nomes de Ivaga'ğa (gente do céu) as crianças Kwandu (KRACKE, 1984b, p. 17).

Peggion (1996) refere-se à constante mudança de nomes entre os Tenharin. Garcia de Freitas (1926) já havia relatado este costume entre os Parintintin. Cita o caso do Parintintin Matikamundé, que se envolveu em freqüentes conflitos com funcionários do posto de atração. Quando retornava para uma nova visita apresentava-se com outro nome, Tukairi e após outro conflito, nova mudança de nome, Euétui (Ventania). Passado algum tempo, sugeriu a troca de seu nome, Euétui, com o de Garcia e passou a usar este último (GARCIA DE FREITAS, 1926, p. 72). Isto nos sugere que, como Gonçalves (1990) observou entre os Pirahã, o inimigo era fonte de nomes.

Provavelmente, os Parintintin possuíam um acúmulo de nomes adquiridos no decorrer da vida. Quando perguntei a um dos velhos o seu nome na língua materna, respondeu: "Eu tenho muitos nomes". Pensativo, por alguns segundos, indicou o nome Agwahiva, nome do instrumento musical confeccionado com sementes de pequiá. Talvez tenha utilizado este nome devido ao contexto da época, pois neste período os Parintintin estavam confeccionando instrumentos musicais e 
ensinando a dança de Yrerupukuhu. Iturui, o antigo cacique, também relatou que possuía mais de um nome.

No caso dos Parintintin atuais torna-se difícil identificar o papel das metades na onomástica. Os Parintintin utilizam comumente o seu nome em português, que são dados por ocasião do nascimento da criança. Os jovens sempre recorriam aos mais velhos da aldeia para confirmar seu nome na língua e, outros, diziam não ter. As crianças não possuíam nomes na língua Kagwahiva, além do nome em português, são chamadas por diminutivos, Raimundo - Raimundinho; ou apelidos, como Pitiquina, Xuxuca. Estes apelidos, na concepção de D. Maria das Graças Parintintin, eram definidos como nomes indígenas. Passados alguns anos, Raimundinho, já um jovem, passou a ser tratado como Raimundo. Da mesma forma Xuxuca passou a ser chamado por Joveliano. Isto nos sugere que estes apelidos em português dados às crianças são uma reelaboração de um dos aspectos do sistema de nominação, "os nomes de brincar", já observados por Kracke (1984b).

Os Tenharin, embora usem mais freqüentemente o nome próprio em português, mantêm a nominação em língua Kagwahiva. Peggion (1996) concluiu que a onomástica Tenharin resultaria da "relação de afinidade com o exterior, nome dado por um afim, nome sobre a cabeça do inimigo, nome de seres divinos" (PEGGION, 1996, p. 22). Albertino, um chefe de grupo doméstico Tenharin, relatou que se chamava Kairana, mas, na próxima festa Mbotava, mudaria seu nome para Kainãni'ga, provavelmente este seria o seu último nome adquirido.

Kracke (1984a), entre os Parintintin, identificou que o nome era dado pelo tio materno, que reivindicava a criança para si como um afim. Presenciei vários nascimentos na aldeia, relatarei um deles em que a criança recebeu um nome na língua materna. Enquanto todos aguardavam o comunicado do sexo da criança, os avôs paternos discutiam o nome em Kagwahiva da criança. Perguntei ao avô materno qual o nome da criança, imediatamente ele me falou que aguardava a decisão dos avôs paternos. Este relato parece estar de acordo com a descrição de 1928, sobre nascimento e nominação dos recém-nascidos. Conforme relatórios do SPI:

O nome do nascituro, entretanto, constitue um segredo até para própria genitora, pois somente ao avô, e na 
ANGELA KUROVSKI - Distantes e próximos ...

falta deste só pae, é conferido o direito de por o nome da creança, isto até ó primeiro mês da criança, de ahi em diante por diante, poderá a mãe do curumí escolher o nome que the aprouver.

Nunca isto, porém, acontece, porque o avô, ou o pãe, reunida a tribu faz o seu unibe, que afinal é uma canção onde se exaltam, as glórias dos antepassados da grei, dando-se, então, o nome do nascituro, que é repetido, numa espécie de coro, pelos ouvintes (AMAZONAS E ACRE, 1929, p. 22).

Certa ocasião, os Parintintin debateram sobre o desuso dos nomes próprios em língua Kagwahiva, fato que propiciou a realização de um ritual público de nomeação. Os mais velhos tocaram yreru e nominaram os jovens que não possuíam nomes na língua Kagwahiva. Parece que a nominação esteve amparada em critérios, como: características pessoais, habilidades ou feitos, nomes de seres mitológicos e de animais. Quando se referem ao nome indígena masculino acrescentam a palavra $\breve{g} a^{5}$ e aos nomes femininos hĕa ${ }^{6}$. Ex: Tapi'ira'ğa, Tapiira - anta, ğa - ele; Nhambuí' hĕa - nambu pequeno, hĕa - ela.

Se tentarmos relacionar a nominação com a classificação das coisas pertencentes a uma ou outra metade, poderíamos supor que, de fato, nos exemplos citados abaixo, alguns nomes masculinos e femininos podem nos sugerir a que metade o indivíduo pertence. Por exemplo, Aruka (ser mitológico que sobe aos céus), Pirovaí (ser mitológico que sobe aos céus), são nomes de gente do céu, relacionados à metade Kwandu. Kwandurana (espécie de gavião), Kaite'í (macaco-prego), Tarave (arara maracanã), animais, objetos da lista Kwandu, são nomes de pessoas pertencentes à referida metade. Da mesma forma, nomes femininos, como Nhãjia (peixe do qual Mbahira fez a mulher) é um nome da metade Myty̆ e Kwandu'i (gavião pequeno) da metade Kwandu. Contudo não poderia ir além destas suposições.

Alguns exemplos de nomes indígenas, seguido ao lado pela letra $\mathrm{K}$ - Kwandu e M - Myty̆ indicam a respectiva metade do dono do nome, na tabela abaixo:

\footnotetext{
${ }^{5} \mathrm{Ga}$ gaha -ele, pronome masculino - terceira pessoa do singular - ou pronome que indica posse - deles.

${ }^{6}$ Héa -ela, pronome feminino, terceira pessoa do singular - ou indicando posse - dela.
} 
ANGELA KUROVSKI - Distantes e próximos ...

Tabela 2. Nomes Parintintin e metades exogâmicas (elaboração própria).

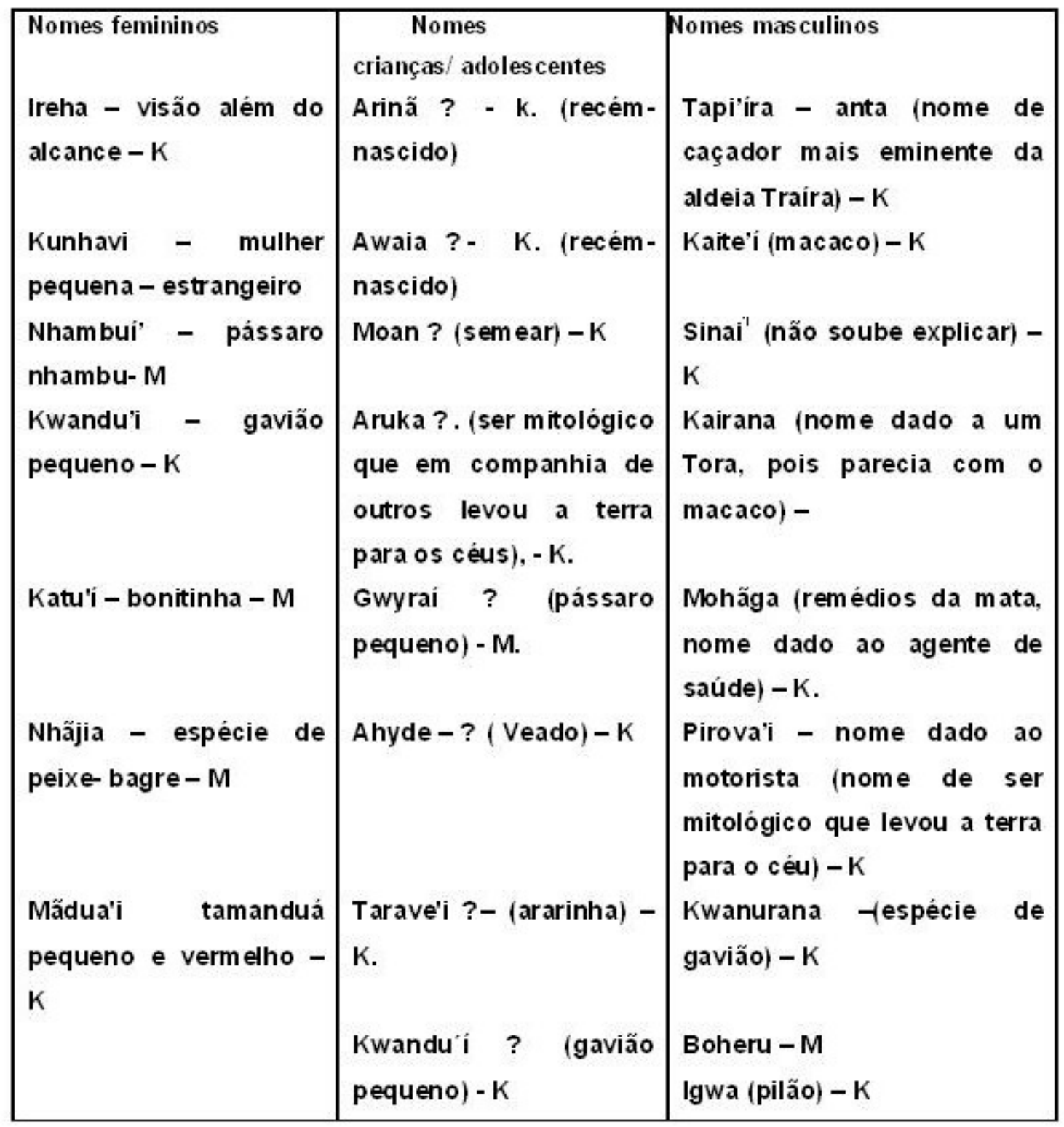

Acredito que a nominação masculina, também, esteja pautada em acontecimentos especiais na vida de uma pessoa ou feitos que realiza, além disso, a mudança de nome exige a ocorrência de algum evento que marque a passagem, como podemos observar no caso de Moan (semear milho). Moan recebeu este nome, porque recentemente tinha plantado uma roça de milho, motivo de orgulho para seus pais, já que se tratava de um pré-adolescente. Coincidência ou não, Igwa (pilão) quando nos 
comunicou o seu nome na língua Kagwahiva, havia concluído a fabricação de um pilão para o Museu da Escola. Da mesma forma que Mbohava/borduna, nos relatos Parintintin, é o mesmo nome daquele que inventou este instrumento. Por sua vez, a nominação feminina hipoteticamente está amparada em características pessoais e também em associações entre o aspecto físico da pessoa e um animal.

Embora Kracke (1984a) classifique este o sistema de nominação baseado em metades como "frouxo no seu funcionamento", tendemos a concordar com Lopes da Silva (1986) que não devemos ver esta "fluidez" como um atributo negativo, definido pela ausência de uma harmonia estabelecida a priori, mas como uma força própria do sistema, e que, portanto demandariam pesquisas mais aprofundadas sobre a significação dos nomes Kagwahiva e sua relação com o sistema dualista.

Por fim poderíamos questionar se haveria algum tipo de classe de idade entre os Parintintin. No período em que convivi com eles, nenhum dos Parintintin se referiu a qualquer diferença interna às metades, baseada no critério de idade. Apenas tenho alguns dados sobre os ritos de passagem de jovens para a fase adulta. Atualmente a cerimônia da menina moça não é mais realizada pelos Parintintin, mas obtivemos informações desta prática entre os Tenharim. Por ocasião da primeira menstruação a menina-moça é mantida reclusa, por oito dias, em um ambiente isolado, submetida a uma espécie de dieta alimentar. Passado este período, a menina é trazida por seu pai à casa do avô paterno, onde se encontram membros de sua família e parentes. Neste local é pintada e enfeitada por uma das tias paternas. Em seguida o avô paterno canta e reza para a menina. Logo em seguida, guerreiros simulam um ataque ao local. A menina é levada à beira do rio, onde FZ lava suas mãos e rosto. No decorrer de cinco dias, a menina seguirá uma dieta alimentar e deverá apresentar um comportamento reservado.

Nos relatos de Garcia de Freitas (1926) o aparecimento da primeira menstruação era saudado publicamente com gritos de guerra e lançamento de flechas pelo pai e parentes. No caso dos meninos, o uso do Kaa (estojo peniano, confeccionado de doze folhas de uma heliconia arumã) indicava sua passagem para uma nova categoria de idade. Segundo também relatos de Garcia de Freitas (1926) este fato era anunciado publicamente com gritos de guerra e lançamento de flechas. 
ANGELA KUROVSKI - Distantes e próximos ...

Os jovens permaneciam um período na mata, empregando-se em caçadas. Quando retornavam eram recebidos novamente com gritos e disparos de flechas. Maria das Graças também nos relatou que a coragem e a realização de empreendimentos guerreiros eram atributos louváveis nos jovens.

Apresentado alguns aspectos sobre a função desempenhada pelas metades no cerimonial e na nominação, passarei a tratar do papel das metades exogâmicas como reguladoras de alianças matrimoniais. 0 casamento Parintintin se dá pela troca de irmãs, casamento de primos cruzados e incorporação de aliados. A presença de linhas entre os Parintintin, segundo Kracke (1984a), é um fator determinante nas possibilidades de casamento. As patrilinhias surgem no acordo realizado entre dois indivíduos na troca de irmãs ou mais geralmente de filhos, continuando nas gerações subseqüentes, resultando na permanente aliança e troca por matrimônio entre a linha do irmão da esposa e do marido, ou seja, na geração seguinte há o retorno de um germano cruzado cedido (KRACKE, 1984a, 109).

Vejamos atualmente como os casamentos Parintintin estão ocorrendo. Tomemos o exemplo da unidade de Agwahiva que estendeu suas alianças para o maior número de outras unidades. Na primeira geração ocorreu a troca de irmãs entre as unidades. Dois de seus filhos germanos (masculino), em segunda geração, entretanto irão projetar suas alianças para outros povos indígenas (Tora e Apurinã) e regionais da Transamazônica. Contudo a aliança com a unidade de Francisco é renovada na segunda geração, como podemos observar na figura seguinte.

Consta também na figura abaixo um caso de acordo de casamento entre filhos de Antonio e de Agwahiva por ocasião do nascimento de uma das filhas daquela unidade, o que confirmaria a reciprocidade entre doadores e recebedores e renovaria a aliança entre as duas unidades que trocaram na geração anterior. A unidade recebedora de uma esposa doaria uma filha para a segunda geração de Agwahiva, no entanto tal compromisso foi desfeito recentemente, ainda que a moça estivesse grávida. Ao que tudo indica, segundo relatos, ocorreu uma disputa entre pai e sogro sobre o lugar de residência futura do rapaz. Como se tratava de dois chefes, que residiam em aldeias diferentes, ambos, se 
consideravam com prestígio suficiente para reivindicar o rapaz. O compromisso foi desfeito, e o filho gerado desta união, que não foi formalizada, ficou aos cuidados da unidade do pai da mãe. O rapaz recentemente casou-se com uma Apurinã co-residente.

Figura 1. Casamentos por trocas (elaboração própria).

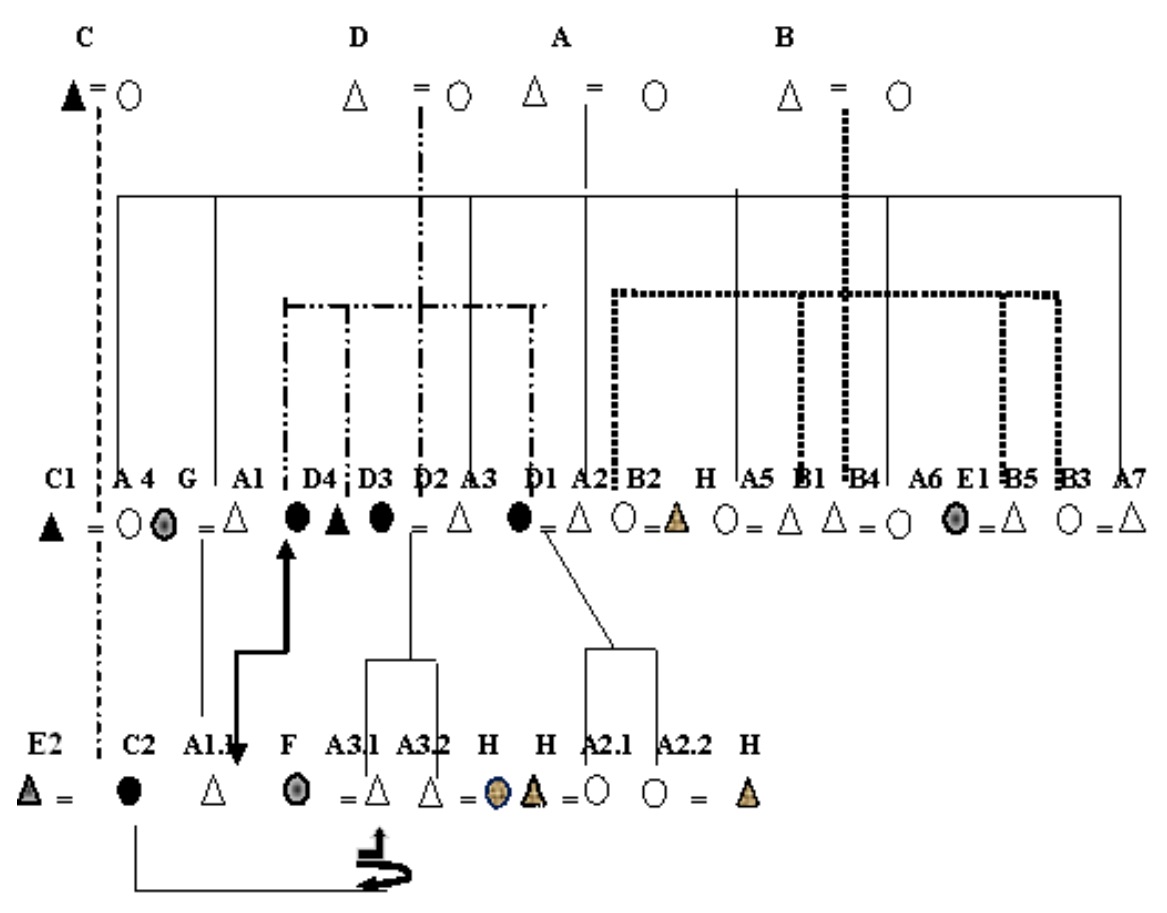

Podemos também constatar que existe uma tendência, ainda que incipiente para projeção de alianças a outros povos indígenas residentes no território Parintintin e regionais. Contudo presenciei várias conversas entre os pais sobre possibilidades de casamento entre as unidades de Agwahiva e Iturui em segunda geração, mas que não se configuraram como acordos formais. Tais possibilidades somente poderão ser confirmadas como fato real quando estas crianças atingirem a idade para casamento. A configuração dos casamentos por trocas nos leva a 
ANGELA KUROVSKI - Distantes e próximos ...

concordar com Peggion (1996) de que as patrilinhias, sugeridas por Kracke (1984a), não são unidades perpétuas de troca, ou seja, um indivíduo tanto pode continuar as alianças estabelecidas por seu pai, como pode ocorrer que um dos filhos projete suas próprias alianças a outros grupos que não aqueles com os quais seu pai realizou trocas (PEGGION, 1996, p. 98).

Como já mencionei, existe uma tendência para casamentos por trocas com outros grupos indígenas e regionais, apontando para a busca de aliados no exterior. Enquanto que para Kracke (1984a) a busca de aliados está além e acima do funcionamento das metades, Peggion argumenta que é exatamente a incorporação de estrangeiros que explicaria a forma das metades. Para o autor os estrangeiros são sempre Taravé, ou seja, a metade Myty̆ se refere ao interior e metade Kwandu/Taravé incorpora o exterior (PEGGION, 1996, p. 62). A classificação social em metades está subordinada à distância geográfica e genealógica, uma vez que indivíduos não co-residentes, mas pertencentes a povos Kagwahiva podem contrair casamento, ainda que sejam da mesma metade. Peggion (1996) irá definir algumas regras que ditam as possibilidades de incorporação de estrangeiros de acordo com o sistema de metades:

- Entre cognato e não cognato co-residentes o casamento é exclusivamente exogâmico;

- Entre estrangeiro e Tenharin o indivíduo é incorporado na metade Tarawé e pode se casar em qualquer metade;

- O sistema de metades coaduna-se com o conceito escalar de distância presente no dravidianato amazônico. Pois, segundo dados do autor, não existiam casos de estrangeiros incorporados à metade Myty;

- As verdadeiras unidades exogâmicas estão no interior das metades, na forma de um complexo sistema patrifiliativo que surge da aliança matrimonial entre dois grupos agnáticos. Cada filho

\footnotetext{
7 Em uma ocasião na aldeia, os Parintintin comentavam sobre as metades e classificaram meu companheiro na metade Kwandu. Perguntei-lhes, em seguida, que metade eu pertenceria, os Parintintin imediatamente acrescentaram: "Se ele é Kwandu [referiam-se ao meu companheiro], você só pode ser Myty̆" (entrevista realizada em 1996). Obviamente que os Parintintin ao nos classificarem desta forma estavam amparados no ideal de casamento. Este comentário dos Parintintin difere do ocorrido com Peggion entre os Tenharin, tanto este antropólogo quanto sua esposa foram classificados, ambos, de Kwandu/Tarave. Peggion (1996) assinala que não há casos de estrangeiros classificados em metades que não seja a Kwandu, ou seja, para os Tenharin os estrangeiros são sempre Kwandu/Tarawe.
} 
ANGELA KUROVSKI - Distantes e próximos ...

com o tempo, após a morte de seu pai, estabelece sua própria relação, constituindo em torno de si uma nova unidade de troca. Cada unidade trocadora (troca homens e mulheres) tem no seu centro um sênior, caracterizando um sistema de troca multibilateral. Estas unidades de troca de cônjuges no interior das metades não permitem que o sistema de metades constitua-se como duas macro-classes matrimoniais. Cada unidade estabelece suas próprias alianças com várias outras, mas que nunca se reduzem a apenas duas. Os Tenharin operam com um sistema multibilateral apesar de possuírem metades (PEGGION, 1996, p. 63).

O argumento de Peggion (1996) aponta à incorporação inevitável de estrangeiros na metade Kwandu, todavia, no caso estudado, encontram-se diferenças. Em geral a regra de descendência é a criança herdar a metade do pai, entretanto, no caso de mulheres Parintintin casadas com regionais considera-se a metade a do pai da mãe. O caso de Nhãjia'í Parintintin é um exemplo entre tantos outros ocorridos: filha de regional com mulher Parintintin foi classificada na mesma metade do MF, Myty̆. Do mesmo modo que nos casamentos entre mulheres Parintintin e homens indígenas de outras etnias, a metade considerada é também a metade a do pai da mãe ${ }^{8}$. Isto nos leva a questionar as razões da não incorporação de Nhãjia'í na metade Kwandu, já que seu pai é um

\footnotetext{
${ }^{8}$ Ao longo do texto citei que nos casamentos entre Parintintin e Tenharin, os filhos foram identificados por estes últimos, como Tenharin. Ao contrário, nos casamentos de mulheres Tenharin com homens Jahoi, os filhos foram identificados como Jahoi. Segundo informações nativas, no caso dos Jahoi, trata-se um acordo entre os dois grupos para evitar a extinção destes últimos. Sabe-se também, ou pelo menos é o que se tem notícia, que as rivalidades e guerras xamânicas ocorriam mais intensamente com os Jahoi, do que com os outros grupos Kagwahiva. Assim, a descrição destes três casos (Parintintin, Tenharin e Jahoi) nos leva a questionar quais os fundamentos que estão sendo acionados para o reconhecimento da filiação e descendência. Parece que pode estar subjacente o princípio de englobamento, e nestas relações de alianças podem estar em jogo vários critérios, como prestígio de um grupo sobre outro. Veja, para os Parintintin os filhos de Parintintin e brancos e ou de outras etnias são transformados em Parintintin, por sua vez, no caso Tenharin, são os Parintintin englobados pelos Tenharin, e os filhos destas uniões considerados Tenharin. Também nos remete a pensar se há uma teoria da concepção subjacente. Até onde vai meu conhecimento, na antiga teoria da concepção Parintintin, as crianças eram sonhadas pelo xamã e o sêmen do pai contribuía para a formação do bebê. Mas, como vimos, no caso de mulheres casadas com homens estrangeiros, a descendência é traçada pelo pai da mãe. Ademais, nos dias de hoje, não existe mais a figura física do xamã. Por outro lado, os Parintintin tomaram conhecimento de outras teorias de concepção, quer seja pela formação recebida pelos agentes de saúde e ou pelo convívio com a sociedade nacional. Infelizmente, a ausência de dados mais aprofundados de minha parte sobre como os Parintintin pensam, na atualidade, a concepção de seus filhos, não nos permite avançar mais nesta discussão. Além disso, parece que estamos tratando de regras em formação.
}

Espaço Ameríndio, Porto Alegre, v. 3, n. 1, p. 61-83, jan./jun. 2009. 
ANGELA KUROVSKI - Distantes e próximos ...

estrangeiro? Que categorias estão sendo acionadas pelos Parintintin para classificar filhos de casamento com estrangeiros?

Minha hipótese é que ainda as categorias Kagwahiva de humanidade podem estar sendo acionadas. O branco está classificado como Tapy (outro), que mesmo transformado em afim, continua a representar a alteridade. Assim, parece que a relação Tapy/Nós quando trazida para o interior precisa ser domesticada, precisa de alguma forma ser co-substancializada. No caso de pais estrangeiros não está em jogo à descendência patrilinear, mas o gradiente classificatório Parintintin (Kagwahiva/Outro). No interior, as metades operam definindo dois grupos distintos com os quais se deve trocar. Mas, à medida que se ultrapassa o âmbito local e se buscam afins no exterior, não há necessidade de se recorrer exclusivamente ao princípio classificatório das metades, já que o sistema de metades coaduna-se com o gradiente "distante e próximo" que garante a diferenciação. Contudo, na classificação dos filhos gerados destas alianças matrimoniais com o exterior tudo se passa como se a alteridade devesse gradativamente diminuir, dando lugar à consangüinidade, esta englobando a afinidade. Ou seja, trata-se do princípio de "englobamento", a maneira dumontiana (DUMONT, 1992); num primeiro momento a consangüinidade é englobada pela afinidade e posteriormente se dá o inverso. Afinidade e consangüinidade fazem parte de uma mesma estrutura que oscila entre dois pólos, cada termo, ora englobando ora sendo englobado (VIVEIROS DE CASTRO e FAUSTO, 1993).

Assim proponho um modelo de organização dual Parintintin que pressupõe duas formas de estrutura, uma concêntrica - relação dentro e fora, próximo e distante, Tapy aliado e Parintintin, na qual impera um princípio de atração da afinização para consaguinização dos filhos de estrangeiros não Kagwahiva; e outra diametral, relação simétrica entre metades - predominando no âmbito local - na qual o princípio das metades é o princípio englobante e a afinidade vai englobar a consangüinidade. O gradiente funciona como um fator de atração da afinidade e filtro transformador dela em consangüinidade. Conforme figura abaixo: 
ANGELA KUROVSKI - Distantes e próximos ...

Figura 2. Modelo de organização dual Parintintin (elaboração própria).

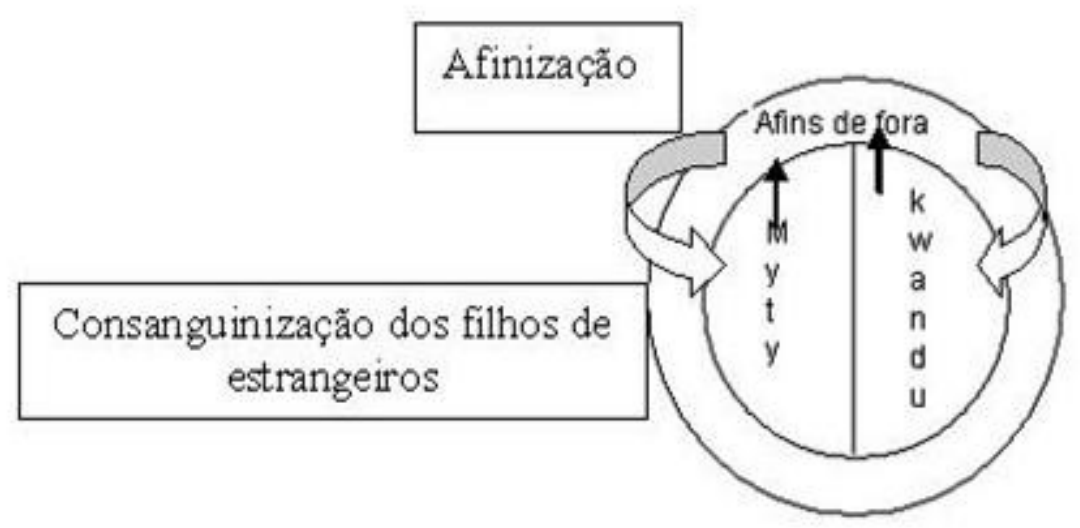

$\mathrm{Na}$ atualidade, mesmo que existam restrições para 0 funcionamento ideal do sistema dualista, as metades possuem um valor ideológico para os Parintintin. Sendo assim, não nos parece necessário postular que seja um empréstimo de instituições de outros povos, como nos sugeriu Kracke. Nimuendaju já havia observado, à época do contato, que não teve dificuldades em descobrir qual metade pertenciam os indivíduos Kagwahiva, pois tão logo chegavam declaravam: "Sou Mitú! Sou Kwandú!" (NIMUENDAJU, 1924, p. 72). Consideravam inteiramente inconcebível que os funcionários do posto não pertencessem a uma das metades referidas.

Possivelmente a depopulação sofrida pelos Parintintin no decorrer do processo de contato, corroborou para afetar este sistema dualista de representação, criando as condições para o surgimento da categoria Gwyră̌'gwara 9 . Afirmam os Tenharin, que esta categoria somente é encontrada entre os Parintintin. Contudo, aqueles, na época do contato, também foram obrigados a fazer alguns rearranjos nas trocas

\footnotetext{
${ }^{9}$ Wagley (1988), em suas análises sobre a organização social Tapirapé, menciona que para os Tapirapé o número populacional garantia o funcionamento de suas instituições. A aldeia deveria ter gente suficiente para sustentar vários grupos de parentesco, fornecendo associados às inúmeras Associações de Pássaros e membros para todos os grupos de Festa. Com a intensificação do contato, muitas mudanças ocorreram e, em 1965, por ocasião de uma nova visita à aldeia, Wagley observou que as Associações de Pássaros ainda funcionavam, embora com menos rigor que antigamente. Do mesmo modo no caso Suruí, Laraia (1986) aponta que a depopulação sofrida pode ter obrigado essa sociedade a tornar mais amplo intercâmbio matrimonial entre clãs.
} 
ANGELA KUROVSKI - Distantes e próximos ...

matrimoniais para manter o sistema em funcionamento. Menendez (1989) observou que o ciclo matrimonial Kagwahiva Tenharin estava baseado numa exogamia interna do grupo. Mas, nos anos 70, com a abertura da Transamazônica, muitos Tenharin foram vítimas de doenças com óbitos, e este fato acarretou escassez de cônjuges no grupo local. Tal situação levou-os a praticar alguns casamentos que implicaram em uma exogamia local, Tenharin/Parintintin, Tenharin/Jahoi.

Se analisarmos os atuais casamentos Parintintin, concluiremos sobre a restrição em se estabelecer uniões conjugais entre as metades exogâmicas. Conforme dados da tabela abaixo:

Tabela 3. Dados numéricos de pessoas por metades (elaboração própria).

\begin{tabular}{|c|l|c|c|}
\hline Aldeia & $\begin{array}{l}\text { Número de pessoas } \\
\text { Myty }\end{array}$ & $\begin{array}{l}\text { Número de } \\
\text { pessoas Kwandu }\end{array}$ & $\begin{array}{l}\text { Número de } \\
\text { pessoas de } \\
\text { outros povos }\end{array}$ \\
\hline A & $\begin{array}{l}\text { 06, dos quais 03 } \\
\text { solteiros. }\end{array}$ & 44 & 09 \\
\hline B & 09 & 17 & 10 \\
\hline
\end{tabular}

O quadro acima revela um desequilíbrio entre a quantidade de pessoas Myty̆ em relação à Kwandu. Os dados apontam para a impossibilidade futura de se manter em funcionamento o sistema dualista apenas com cônjuges locais, já que a maioria da população em possibilidade de casamento pertence à metade $K$ wandu e o princípio de transmissão é em linha paterna. Todavia, os Kagwahiva Parintintin continuam se identificando em metades e se reportando ao ideal de casamento entre Myty̆ e Kwandu.

Existem duas versões apresentadas pelos Parintintin para explicar esta situação. Na primeira, os casamentos Kwandu/Kwandu ocorridos não são considerados ideais e estão classificados como Gwyray̆'gwara. Gwyray̆'gwara nos foi traduzido como "pássaro mexido, misturado". Uma forma de casamento não ideal, "que não conserta mais". (I. Parintintin, entrevista realizada em 1996). O assunto é considerado tabu 
ANGELA KUROVSKI - Distantes e próximos ...

e, portanto, não comentado em público. Todavia nenhum Parintintin que realizou casamento em uma mesma metade identifica-se como Gwyray̆'gwara. Caso, questionados sobre qual a metade pertencem, logo se autodenominam em uma das metades oficiais.

Se assim for, os Parintintin têm conhecimento que casamentos em uma mesma metade significam o rompimento da regra, mas, diante da impossibilidade de mantê-la, procuram justificar sua opção ou simplesmente evitam tocar no assunto e não se denominam Gwyray̆gwara. Esta situação nos reportaria a clássica distinção de Leach (1995) entre ideal e norma ${ }^{10}$, já sublinhada por Malinowski em 1922. Afirma Leach que

entre a teoria e a prática do sistema de casamento kachin se encontram consideráveis discrepâncias. O sistema mayu - dama parece rígido e complexo, mas na prática possui uma flexibilidade que permite aos Kachin falar como se estivessem ajustando-se às normas mayu-dama (LEACH, 1995, p. 137).

Para ilustrar, destacamos o depoimento de um indivíduo Kwandu casado com mulher Kwandu; quando perguntei sobre a existência da categoria Gwyray̆'gwara, mostrou-se bastante envergonhado e justificou: "Sou criticado porque casei com minha prima, mas branco também casa com prima” (“D.”, entrevista realizada em 1996).

Contudo se considerarmos, como afirma Lopes da Silva (1986), que, nas sociedades sul-americanas, a existência de uma flexibilidade na vinculação de indivíduos a grupos, mais que apontar para arranjos contextuais, é antes prevista estruturalmente, parece-me fundamental recuperar a segunda versão registrada por Schroeder (1995). O depoimento de Manoelzinho Parintintin justifica a possibilidade de casamentos em uma mesma metade desde que os cônjuges sejam de outro local e não aparentados entre si. Este argumento de Manoelzinho referendaria as conclusões de Peggion (1996) que casamento entre cognatos e não cognatos não co-residentes podem ser realizados dentro de uma mesma metade, sem que isto implique um rompimento completo da regra. Neste caso o critério de distância geográfica e genealógica estaria sendo acionado. Mas, ainda que as duas unidades

${ }^{10}$ Cf. Leach (1995) para o caso Kachin.

Espaço Ameríndio, Porto Alegre, v. 3, n. 1, p. 61-83, jan./jun. 2009. 
familiares trocadoras da aldeia estejam classificadas na mesma metade Kwandu, vale destacar que a distribuição das responsabilidades econômicas entre os dois grupos denotam uma oposição simétrica na aldeia, vejamos: um dos filhos do grupo local se responsabiliza pela caça, enquanto o filho do grupo migrante é responsável por coordenar as atividades agrícolas, isto nos sugere uma alusão às metades, Myty̆. agricultura:: Kwandu: caça.

A despeito das duas versões, o fato é que os Parintintin quando se referem ao casamento ideal, reportam-se à exogamia de metades. Deste modo, mesmo estando correto o argumento de Manoelzinho, futuramente, os eventuais casamentos que porventura ocorram entre co-residentes da mesma metade, representariam o rompimento da regra e, portanto, dariam origem ao surgimento dos Gwyray̆'gwara. Sendo assim, se o casamento ideal é a exogamia de metades, e se o discurso de I. Parintintin tem fundamento, as uniões em uma mesma metade resultariam num grave problema para a identidade Parintintin. Isto nos leva a pensar que a busca de casamentos inter étnicos, mais do que apontar para um desuso dos princípios estruturais próprios e, portanto para uma integração dos Parintintin à sociedade nacional, frisa exatamente o contrário, uma aplicação destes princípios como forma de escapar da não humanidade, do incesto. A busca de aliados no exterior parece, pois, estar em correspondência com o sistema dualista de metades exogâmicas; ou seja, não existe contradição entre a busca de aliança com o exterior e o princípio das metades. Como afirma Viveiros de Castro (2000), o Outro é primeiro de tudo um Afim.

A afinização de outrem ocorre a despeito do fato que a vasta maioria das alianças matrimoniais efetivas se firmam no interior do grupo local, mas tais alianças não podem se concentrar no grupo local (VIVEIROS DE CASTRO, 2000, p. 14).

As reflexões sobre metades e mitologia, que complementariam este breve estudo, constam em outro texto sobre mito cosmológico e metades $^{11}$.

\footnotetext{
${ }^{11}$ Cf. Kurovski (2005).
} 
ANGELA KUROVSKI - Distantes e próximos ...

\section{Referências Bibliográficas}

AMAZONAS E ACRE, Inspetoria. Relatório SPI. Manaus, 1929.

BETTS, La Vera. Dicionário Parintintin - Português, Português - Parintintin. Brasília: Summer Institute of Linguistics, 1981.

DUMONT, Louis. Homo Hierarchicus: o sistema de casta e suas implicações. São Paulo: EDUSP, 1992.

FERNANDES, Florestan. A organização social dos Tupinambá. São Paulo: Instituto Progresso Editorial, 1948.

GARCIA DE FREITAS, José. Os Índios Parintintin. Journal de la Société des Americaistes, Paris, n. 18, p. 67-73, 1926.

GONÇALVES, Marco Antônio T. Nomes e cosmos: onomástica entre os Mura Pirahã. Comunicação, Rio de Janeiro, n. 20, p. 1-37, 1990.

KRACKE, Waud. Force and Persuasion: leadership in Amazônia Society. Chicago/London: The University of Chicago Press, 1978.

. Kagwahiv moieties: form without function? In. KENSINGER, Kenneth M. (org). Marriage practices in lowland South América. Chicago: Ed Urbana/University of Illinois Press, 1984a. p. 99- 124.

Ivaga'nga, mbahira'nga e Anhang - Gente do céu, gente das pedras e demos da mata: espaço cosmológico e dualidade na cosmologia Kagwahiv. In: VIVEIROS DE CASTRO, Eduardo (Org.). Cosmologia Tupi. Associação Brasileira de Antropologia, 1984b. (datilografado).

KUROVSKI, Angela. Os abandonados: o mito Kagwahiva. In: Anfitriões guerreiros: um estudo sobre rivalidades e generosidades nos Kagwahiva Parintintin. 2005. 196 f. Dissertação (Mestrado em Antropologia Social) - Programa de PósGraduação em Antropologia Social, UFPR, [2005]. p. 93 -122.

LARAIA, Roque de Barros. Tupi: Índios do Brasil. Atual. São Paulo: FFLCH-USP, 1986.

LEACH, Edmund R. Sistemas políticos da Alta Birmânia. São Paulo: EDUSP, 1995.

LEVI-STRAUSS, Claude. Estruturas elementares do parentesco. Petrópolis: Vozes, 1982.

Antropologia estrutural dois. Rio de Janeiro: Tempo Brasileiro, 1993.

Espaço Ameríndio, Porto Alegre, v. 3, n. 1, p. 61-83, jan./jun. 2009. 
ANGELA KUROVSKI - Distantes e próximos ...

Antropologia estrutural. Rio de Janeiro: Tempo Brasileiro, 1996.

. O pensamento selvagem. São Paulo: Papirus, 1997.

LOPES DA SILVA, Aracy. Nomes e amigos: da prática xavante a uma reflexão sobre os Jê. São Paulo: FFLCH/USP, 1986.

MENENDEZ, Miguel Angel. Os Tenharin: uma contribuição para o estudo dos Tupi Centrais. 1989. Tese (Doutorado em Antropologia Social) - FFLCH, Universidade de São Paulo, [1989].

NIMUENDAJU, Curt. Os Índios Parintintin do Rio Madeira. Journal de la Société dês Américanistes, Paris, n. XVI, p. 201-278, 1924.

PEGGION, Edmundo A. Forma e função: uma etnografia do sistema de parentesco Tenharin (Kagwahiv, AM). 1996. 127 f. Dissertação (Mestrado em Antropologia Social) - Universidade Estadual de Campinas, [1996].

Na certeza de contarmos com Vossa Valorosa Presença: o ritual Mbotawa entre os Tenharin do rio Marmelos. In: Anais da XXIV Reunião Brasileira de Antropologia. Olinda: ABA, 2004.

RODRIGUES, Ayron D. Línguas brasileiras: para o conhecimento das línguas indígenas. São Paulo: Loyola, 1986.

SCHROEDER, Ivo. Indigenismo e política indígena entre os Parintintin. 1995. 164 f. Dissertação (Mestrado em Educação Pública) - Universidade Federal do Mato Grosso, [1995].

TURNER, Terence. De cosmologia a história: resistência, adaptação e consciência social entre os Kayapó. In: VIVEIROS DE CASTRO, Eduardo; CARNEIRO DA CUNHA, Manuela (Orgs.). Amazônia, Etnologia e História Indígena. São Paulo: NHII/USP/ FAPESP, 1993. p. 43-66.

VIVEIROS DE CASTRO, Eduardo. Araweté: os deuses canibais. Rio de Janeiro: Jorge Zahar/ANPOCS, 1986.

O Mármore e a Murta: sobre a inconstância da alma selvagem. Revista de Antropologia, São Paulo, v. 35, p. 21-74, 1992.

Atualização e contra-efetuação do virtual na sociedade amazônica: o processo de parentesco. Ilha Revista de Antropologia, Florianópolis, v. 2, n. 1, p. 05-46, dez. 2000 .

VIVEIROS DE CASTRO, Eduardo; FAUSTO, Carlos. O Parentesco nas Terras Baixas da América do Sul. Rio de Janeiro: Museu Nacional, 1993. 
ANGELA KUROVSKI - Distantes e próximos ...

WAGLEY, Charles. Lágrimas de Boas Vindas: os índios Tapirapé do Brasil Central. Belo Horizonte/São Paulo: Itatiaia/Editora USP, 1988. 